\title{
Taxonomic notes on some species of the genus Zelotes (Araneae: Gnaphosidae) from Korea and Japan
}

\author{
Takahide Kamura \\ Biological Laboratory, Otemon Gakuin University, 2-1-15, Nishi-Ai, Ibaraki, \\ Osaka, 567-8502 Japan \\ E-mail: kamura@res.otemon.ac.jp
}

\begin{abstract}
New taxonomic conclusions on some species of the genus Zelotes (Gnaphosidae) are reported. Z. tintinnus Paik 1986 is synonymized with Z. kimwha Paik 1986. It was detected that the females associated with Z. hayashii Kamura 1987 correctly belong to Z. bifukaensis Kamura 2000, and true female of Z. hayashii is described. Although male Z. flexuosus Kamura 1999 has not been reported, it became clear that a part of the males formerly associated with Z. ryukyuensis Kamura 1999 belongs to Z. flexuosus.
\end{abstract}

Key words - Gnaphosidae, Zelotes, taxonomy, new synonymy, Korea, Hokkaido, Okinawa Pref.

In this paper, new taxonomic conclusions on some species of the genus Zelotes (Gnaphosidae) are reported, namely a new synonymy on species described from Korea, correction on matching of male and female of two species from Hokkaido, and solution to confusion on males of two species from Okinawa Prefecture.

Abbreviations used in this paper are as follows: ALE, anterior lateral eye; AME, anterior median eye; MOA, median ocular area; NY, N. Yasuda leg.; p, proventral; PLE, posterior lateral eye; PME, posterior median eye; $r$, retroventral. Eye size means length of long axis of an eye, but measurement of posterior median eye was made at horizontal level.

I would like to express my sincere thanks to Dr. Hirotsugu Ono, National Science Museum, Tokyo (NSMT), Mr. Nobuki Yasuda, Hokkaido, Mr. Susumu Kaneno, Osaka, Mr. Ken-ichi Kumada, Mie, Ms. Mayumi Matsuda, Hokkaido, Dr. Yoshiaki Nishikawa, Otemon Gakuin University, Osaka, Dr. Makoto Yoshida, Ritsumeikan University, Shiga, and the late Dr. Chiyoko Okuma for loaning or offering the specimens used in this study. My sincere thanks are also due to Mr. Takeshi Sasaki and Mr. Shigenori Karasawa, Ryukyu University, Okinawa, and Dr. Akio Tanikawa, Shichirigahama Senior High School, Kanagawa, for their kind assistance in the field research.

\section{New synonymy}

Zelotes kimwha Paik 1986 was originally described only by a male from Korea and was also recorded from Japan (Kamura 2000). Zelotes tintinnus Paik 1986 was originally described from Korea only by a female. Each opposite sex of these two species has not been reported. I found a male and a female considered to belong to the same single species in specimens collected from Korea, which were offered by the late Dr. C. Okuma. The male and female were identified with Z. kimwha and Z. tintinnus respectively. Therefore I concluded that these two species are synonymous with each other.

\section{Zelotes kimwha Paik 1986}

(Figs. 1-2)

Zelotes kimwha Paik 1986, p. 30, figs. 29-36; Kamura 2000, p. 161, figs. 5-6.

Zelotes tintinnus Paik 1986, p. 32, figs. 37-43. new synonymy

Specimens examined. $1{ }^{\rtimes} 1$ 우, Mt. Sudosan, Gyongsangbug-do, Korea, $350 \mathrm{~m}$ alt., 27-31. V. 1979, K. Yamagishi leg.

Male. Described by Paik (1986) and Kamura (2000).

Female. Described by Paik (1986).

Measurements (based on the specimens shown above, in $\mathrm{mm})$. Body length $\delta^{\top} 6.65$, 우10.13. Carapace length ${ }^{2} 2.95$, + 3.33 ; width 82.35 , + 2.63 . Abdomen length ${ }^{7} 3.70$, + 6.80 ; width $\delta^{2} 2.25$, 우 3.50 .

Ventral spines on legs I and II (based on the specimens shown above). $\delta^{-}$: tibiae: I and II 0-0-0; metatarsi: I and II 2-0-0. ㅇ: tibiae: I and II 0-0-0; metatarsi: I 2-0-0, II 2-1p-0.

Distribution. Korea and Japan (Honshu).

\section{Correction on matching of male and female}

Zelotes hayashii Kamura 1987 and Zelotes bifukaensis Kamura 2000 are known from Hokkaido, Japan. Each of the two species was originally described only by male. Female of the former species was later described (Kamura 1994) and that of the latter has not been reported. After examining specimens collected from Hokkaido, which were loaned by Dr. H. Ono and Mr. N. Yasuda, I recognized males of these two species and females of two forms. Female of the one 

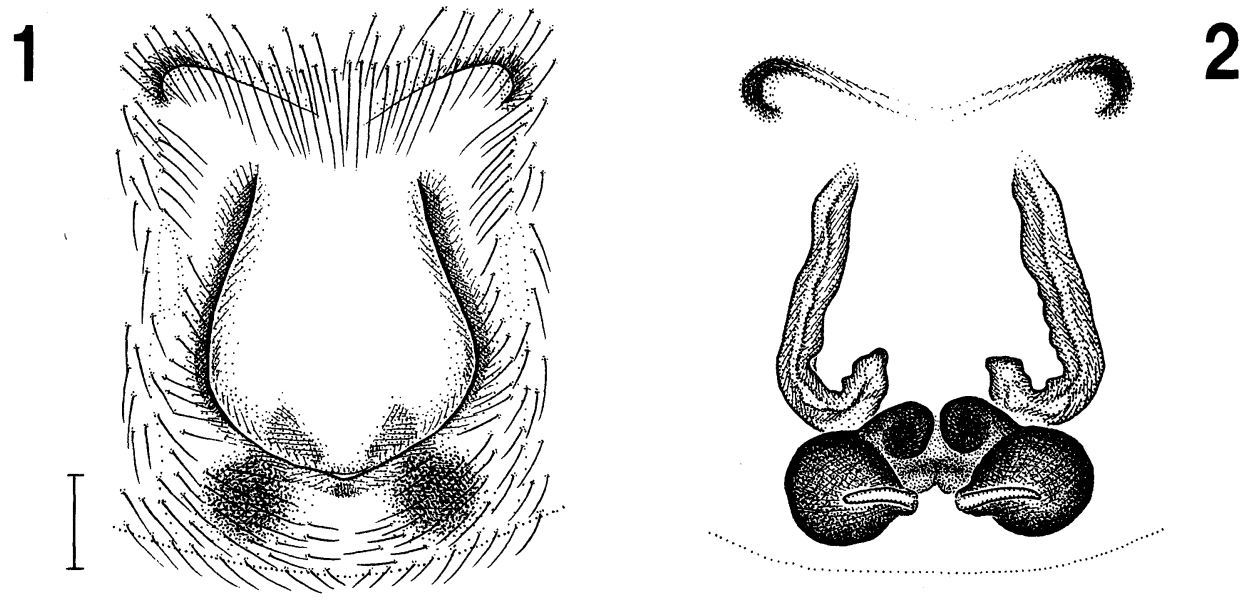

Figs. 1-2. Zelotes kimwha Paik 1986 (Mt. Sudosan, Korea) - 1, Epigynum, ventral view; 2, female genitalia, dorsal view. (Scale: $0.2 \mathrm{~mm}$ )

form was identified with Z. hayashii, and that of the other one was newly found and expected to belong to $Z$. bifukaensis. However, male and female specimens collected from Rebun Island, Rishiri Island and Mts. Daisetsuzan suggested that male of $Z$. bifukaensis and female associated with $Z$. hayashii in Kamura (1994) belong to the same single species (Fig. 7). I concluded that matching of male and female of the two species was erroneous, that is, the females associated with $Z$. hayashii correctly belong to $Z$. bifukaensis, and the newly found females belong to $Z$. hayashii.

\section{Zelotes hayashii Kamura 1987}

(Figs. 3-4, 7)

Zelotes hayashii Kamura 1987, p. 5, figs. 6-7; Matsuda 1988, p. 15, figs. 12-13; Kamura 1994, p. 135 (males only).

Note. Female specimens listed as $Z$. hayashii in Kamura (1994) and Ono (1994) belong to Z. bifukaensis.

Specimens examined other than those listed in Kamura (1994). Teshio-gun, Hokkaido, Japan: 1 ${ }^{\lambda}$, Sarobetsu, Horonobecho, 20. VIII. 1996, A. Kudo leg.; 1우, Sarobetsu, 9. VI. 1991, NY (NSMT-Ar 5320); 1우, Sarobetsu, Toyotomi-cho, 11. VII. 1991, NY. Tomamae-gun, Hokkaido: 1 $\widehat{\delta}^{2}$, Teuri-shima Is., Haboro-cho, 27. V. 1982, K. Kumada leg.

Male. Described by Kamura (1987).

Female. Diagnosis. Female of $Z$. hayashii is similar to that of Z. clivicola (L. Koch 1870) in structure of epigynum (see Grimm 1985, figs. $286 \mathrm{a}, \mathrm{b}$ ), but is distinguished from the latter by having a pair of longitudinal ducts situated medianly in internal genitalia.

Measurements (based on one female collected on 11. VII. 1991 from Sarobetsu, Hokkaido; in mm). Body length 5.95. Carapace length 2.65, width 2.05. Abdomen length 3.30, width 1.80. Eye sizes: AME 0.08, ALE 0.10, PME 0.10, PLE 0.10. Distances between eyes: AME-AME 0.04, AMEALE 0.01, PME-PME 0.04, PME-PLE 0.04, ALE-PLE 0.08 . MOA anterior width 0.19 , posterior width 0.24 , length 0.26 . Clypeus height 0.12 . Length of legs as in Table 1 .

Variation (in $\mathrm{mm}$ ). $\delta^{\lambda}$ : body length $5.10-5.95$; carapace length 2.30-2.70, width 1.90-2.10; abdomen length 2.803.25 , width 1.65-2.03. 우 (one female other than above shown one): body length 7.45 ; carapace length 2.75 , width 2.05; abdomen length 4.70, width 2.75 .

Ventral spines on legs I and II. $\delta^{-}$: tibiae: I 0-0-0, II 0-0-0 or $0-1 \mathrm{r}-0$; metatarsi: I $2-0-0$, II $2-0-0$ or $2-1 \mathrm{r}-0$. 우 : tibiae: I and II $0-0-0$; metatarsi: I $2-0-0,2-1 \mathrm{p}-0$ or $2-2-0$, II $2-0-0$ or 2-2-0.

Distribution. Japan (Hokkaido).

\section{Zelotes bifukaensis Kamura 2000 \\ (Figs. 5-7)}

Zelotes hayashii: Kamura 1994, p. 135, figs. 1-2 (females only, misidentification); Ono 1994, p. 185 (misidentification).

Zelotes bifukaensis Kamura 2000, p. 160, figs. 1-2.

Table 1. Measurements of legs of Zelotes hayashii Kamura 1987 from Sarobetsu (11.VII.1991) (†, in mm).

\begin{tabular}{ccccccc}
\hline Leg & Femur & Patella & Tibia & Metatarsus & Tarsus & Total \\
\hline I & 1.80 & 1.11 & 1.23 & 1.05 & 0.85 & 6.04 \\
II & 1.55 & 0.98 & 1.05 & 0.98 & 0.80 & 5.36 \\
III & 1.38 & 0.78 & 0.85 & 1.06 & 0.73 & 4.80 \\
IV & 2.00 & 1.10 & 1.43 & 1.78 & 0.88 & 7.19 \\
\hline
\end{tabular}


Specimens examined other than those listed in Kamura (2000). Hokkaido, Japan: 4`3 우, Mt. Rebun-dake, Rebun Island, 15.VII.1991, NY (2주우: NSMT-Ar 5321); 1저우, Mt. Rishirisan, Rishiri Island, 1. VII. 1990, NY (NSMT-Ar 5322); 1우, Sarobetsu, Teshio-gun, 9. VI. 1991, NY (NSMT-Ar 5323); 10, Mts. Daisetsu-zan, Kamikawa-gun, 23. VII. 1982, NY; 1ð1우, same locality, 21. VIII. 1982, NY; 1우, Shiretoko, 26-28. VII. 1987, S. Kaneno leg.

Female specimens misidentified with $Z$. hayashii in Kamura (1994) and Ono (1994). Hokkaido: 1오, SW of Mt. Piashiri-yama, Nayoro-shi, 18. VIII. 1990, Y. Nishikawa leg.; 1우, Mt. Teshio-dake, Asahi-cho, Kamikawa-gun, 28. VII. 1988, NY (NSMT-Ar 3189); 1우, Shirikishi-manaigawa, Furano-shi, 8. VIII. 1991, M. Matsuda leg.

Male. Described by Kamura (2000).

Female. Described by Kamura (1994) as Z. hayashii.

Variation (in mm). Body length $\lesssim 4.90-5.90$, + 5.05-7.30. Carapace length $\delta^{\rtimes} 2.20-2.50$, 우2.30-2.95; width $ð 1.75-2.00$,

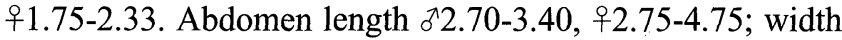
๙11.45-1.68, 우1.60-2.50.

Ventral spines on legs I and II. $\delta$ : tibiae: I 0-0-0, 0-1r-0, $0-2-0$ or $1 \mathrm{r}-2-0$, II $0-1 \mathrm{r}-0,0-2-0,0-1 \mathrm{r}-1 \mathrm{p}, 0-2-1 \mathrm{p}, 1 \mathrm{r}-1 \mathrm{r}-0,1 \mathrm{r}-$ $2-1 \mathrm{p}$ or $1 \mathrm{r}-2-2$; metatarsi: I and II $2-1 \mathrm{r}-0$ or $2-2-0$. 우 tibiae: I $0-0-0$, II $0-0-0$ or $0-1 \mathrm{r}-0$; metatarsi I $1 \mathrm{r}-2-0,2-1 \mathrm{p}-0,2-1 \mathrm{r}-0$ or $2-2-0$, II $2-1 \mathrm{p}-0$ or $2-2-0$.

Distribution. Japan (Hokkaido).

\section{Solution to confusion on males of two species}

Zelotes ryukyuensis Kamura 1999 and Zelotes flexuosus Kamura 1999 are known from Okinawa Prefecture, southwest Japan. Both sexes of $Z$. ryukyuensis and female of $Z$. flexuosus were described, but male of the latter species has not been reported. It was known that in males from Okinawa Prefecture there are two forms which differ from each other in shapes of retrolateral tibial apophysis in palp (Kamura 1999, figs. 20 \& 21). I considered the difference
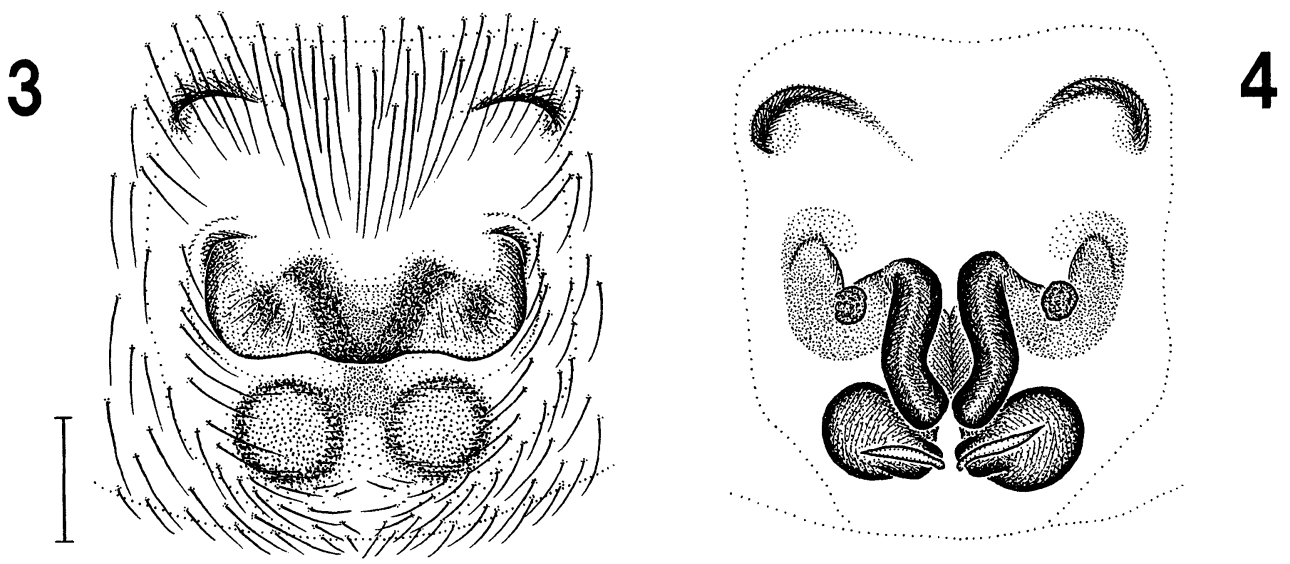

Figs. 3-4. Zelotes hayashii Kamura 1987 (Sarobetsu, Hokkaido, Japan) - 3, Epigynum, ventral view; 4 , female genitalia, dorsal view. (Scale: $0.2 \mathrm{~mm}$ )
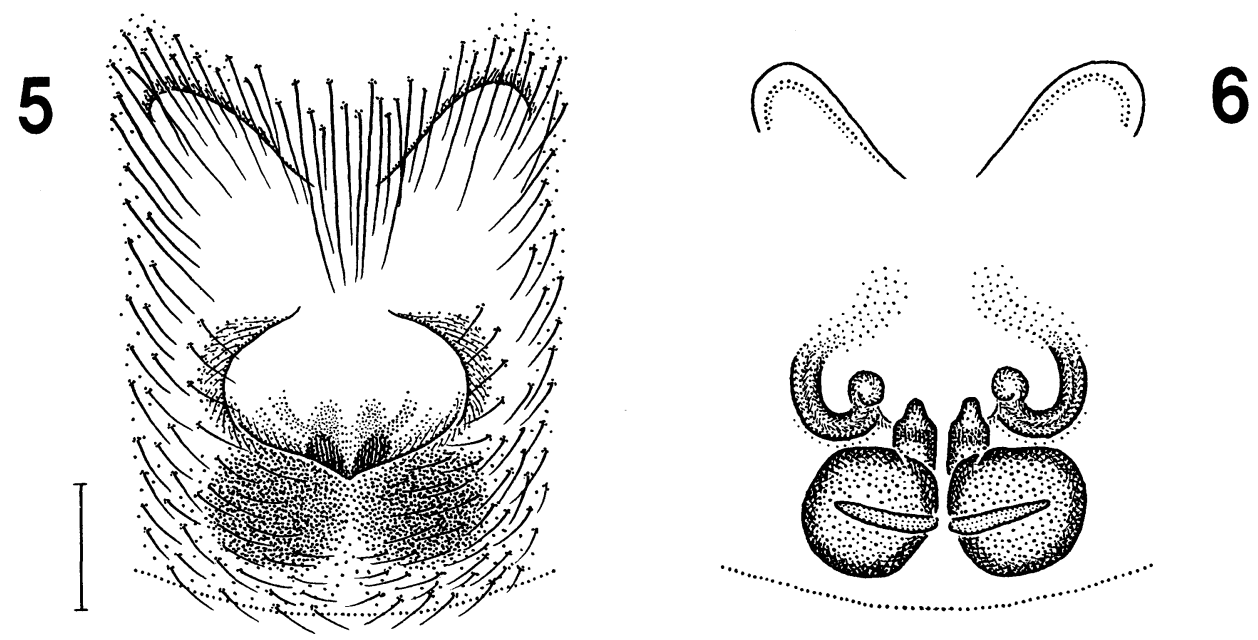

Figs. 5-6. Zelotes bifukaensis Kamura 2000 (Furano-shi, Hokkaido, Japan) - 5, Epigynum, ventral view; 6, female genitalia, dorsal view. (Scale: $0.2 \mathrm{~mm}$ ) 
as variation among individuals of $Z$. ryukyuensis because these two forms are extremely similar in whole the structure of palp except retrolateral tibial apophysis. However, after the research in Okinawa-jima Island in summer of 2002, males of the one form and females of $Z$. flexuosus were collected from same habitat in same locality (Yona, Kunigamison). Therefore I reconsidered that males of the two forms do not belong to same species, that is, a part of the males associated with $Z$. ryukyuensis in the original description (Kamura 1999) belongs to Z. flexuosus.

\section{Zelotes ryukyuensis Kamura 1999}

(Figs. 8-11, 13)

Zelotes ryukyuensis Kamura 1999, p. 86, figs. 21-23 (females and part of males).

Note. In the original description of $Z$. ryukyuensis, two male specimens collected from Yona, Kunigami-son, Okinawa-jima Island were listed and one of them were des- ignated as one of the paratypes (NSMT-Ar 4316), but these males belong to $Z$. flexuosus.

Female. Described by Kamura (1999).

Male. Diagnosis. Males of $Z$. ryukyuensis and $Z$. flexuosus are very similar to each other, and it is impossible to distinguish them by ventral view of palp (see Kamura 1999, fig. 17), but they are separated from each other by a following point. In $Z$. ryukyuensis retrolateral tibial apophysis is pointed and the tip is slightly bifid (Figs. 8- $^{-}$ 11), while it is rounded (Fig. 12) in Z. flexuosus.

Measurements (based on one male from Mt. Otowa-dake, Nakijin-son, Okinawa-jima Island; in $\mathrm{mm}$ ). Body length 4.70. Carapace length 2.10, width 1.75. Abdomen length 2.60, width 1.55. Eye sizes: AME 0.08, ALE 0.12, PME 0.08, PLE 0.12. Distances between eyes: AME-AME 0.04, AME-ALE 0.01, PME-PME 0.04, PME-PLE 0.04, ALEPLE 0.03. MOA anterior width 0.18 , posterior width 0.20 , length 0.24 . Clypeus height 0.10 . Length of legs as in Table 2.

Variation (in $\mathrm{mm}$ ). $\mathrm{o}^{\text {t}}$ : body length 4.70-5.53; carapace

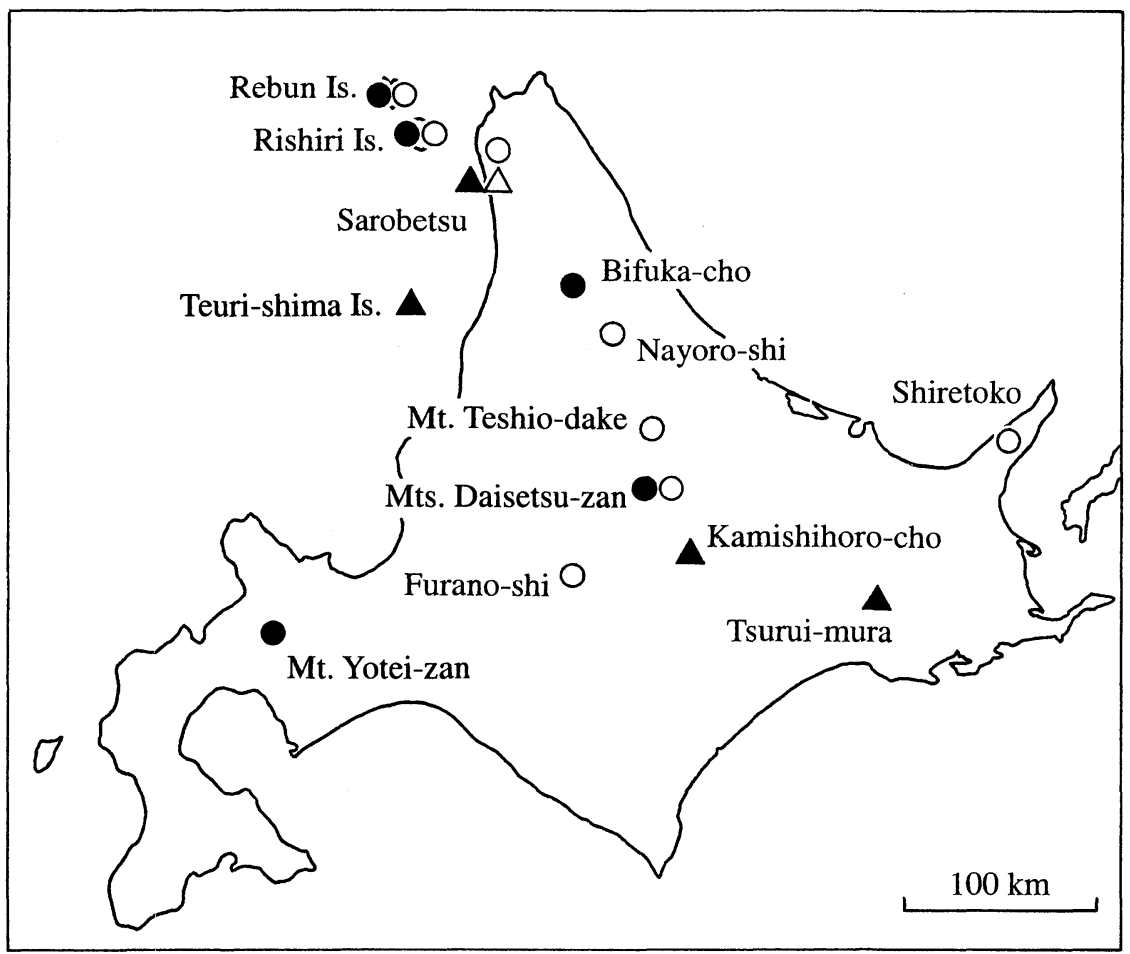

Fig. 7. Collecting localities of two Zelotes species in Hokkaido, Japan. $\mathbf{\Delta}$ : Z. hayashii Kamura 1987 (male), $\triangle$ : same (female), O: Z. bifukaensis Kamura 2000 (male), $\bigcirc$ : same (female).

Table 2. Measurements of legs of Zelotes ryukyuensis Kamura 1999 from Mt. Otowa-dake ( $\overbrace{}^{7}$, in mm).

\begin{tabular}{ccccccc}
\hline Leg & Femur & Patella & Tibia & Metatarsus & Tarsus & Total \\
\hline I & 1.74 & 1.08 & 1.40 & 1.32 & 1.04 & 6.58 \\
II & 1.46 & 0.90 & 1.06 & 1.06 & 0.84 & 5.32 \\
III & 1.30 & 0.70 & 0.87 & 1.06 & 0.68 & 4.61 \\
IV & 1.82 & 1.00 & 1.40 & 1.64 & 0.84 & 6.70 \\
\hline
\end{tabular}



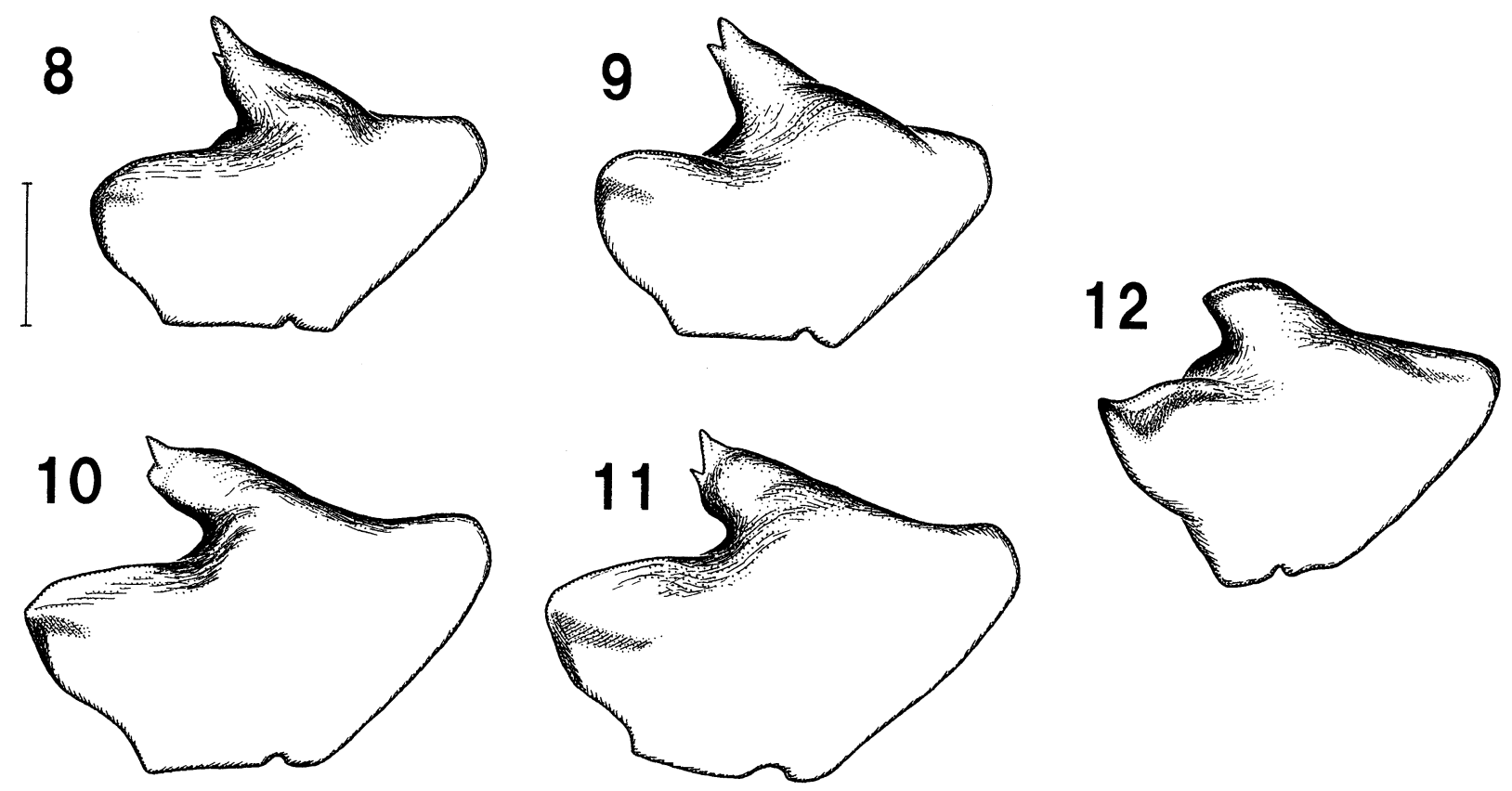

Figs. 8-12. Male palpal tibiae of two Zelotes species from Okinawa Prefecture, Japan (retrolateral view) - 8, Z. ryukyuensis Kamura 1999 (Shuri, Naha-shi); 9, same (Mt. Otowa-dake, Nakijin-son); 10, same (Izumi, Motobu-cho); 11, same (Iheya-jima Is.); 12, Z. flexuosus Kamura 1999 (Yona, Kunigami-son). (Scale: $0.2 \mathrm{~mm}$ )

length $2.10-2.50$, width $1.68-2.05$; abdomen length 2.55 3.03 , width $1.45-1.80$.

Ventral spines on legs I and II. $\sigma^{\top}$ : tibiae: I $0-0-0$, II $0-0-0$, 0-1r-0 1r-1r-0; metatarsi: I 2-1p-0 or 2-2-0, II 2-2-0.

Distribution. Japan (central and southern parts of Okinawa-jima Island, and Iheya-jima Island).

\section{Zelotes flexuosus Kamura 1999}

(Figs. 12-13)

Zelotes ryukyuensis Kamura 1999, p. 86, figs. 17-20 (part of males, misidentification).

Zelotes flexuosus Kamura 1999, p. 88, figs. 24-25.

Specimens examined other than those listed in Kamura (1999). Kunigami-son, Okinawa-jima Island, Okinawa Pref., Japan (Takahide \& Takae Kamura leg.): 5 $\delta^{7} 8$ ㅇ, Yona, $20 \mathrm{~m}$ alt., 25. VII. 2002 (19 matured on 30. VII. 2002). $1 \sigma^{\lambda}, 2 \mathrm{~km} \mathrm{NNW}$ of Mt. Yonaha-dake, 300-320 m alt., 25. VII. 2002. 1ㅇ, $1 \mathrm{~km} \mathrm{SSW}$ of Mt. Fenchiji-dake, 280-300 m alt., 26. VII. 2002.

Male specimens misidentified with $Z$. ryukyuensis in

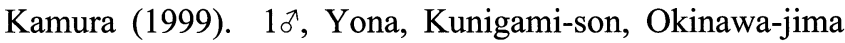
Island, $20 \mathrm{~m}$ alt., 1. IV. 1987, M. Yoshida \& T. Sasaki leg. (NSMT-Ar 4316, designated as one of the paratypes of $Z$. ryukyuensis). 10', same locality, 27 . VII. 1997, T. \& T. Kamura leg.

Female. Described by Kamura (1999).

Male. Described as part of Z. ryukyuensis by Kamura (1999, figs. 17-20). As for the discrimination, see the diagnosis of $Z$. ryukyuensis.

Variation (in mm). Body length $\delta^{\top} 4.03-5.78$, ㅇ 4.30-6.36.

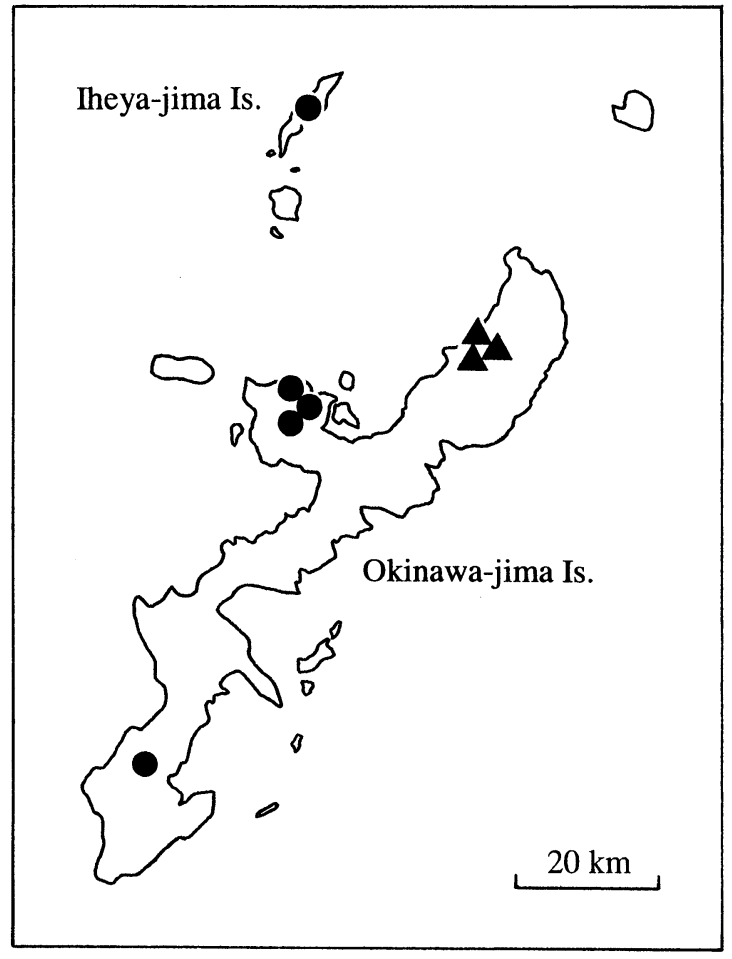

Fig. 13. Collecting localities of two Zelotes species in Okinawa Prefecture, Japan. : Z. ryukyuensis Kamura 1999, $\mathbf{\Delta}: Z$. flexuosus Kamura 1999.

Carapace length $\delta^{7} 2.03-2.48$, ㅇ 2.00-2.78; width ${ }^{\top} 1.63-1.98$, 우 1.45-2.10. Abdomen length $\delta^{\top 2} 2.00-3.30$, 우2.30-3.58; width ${ }^{\top} 1.35-1.90$, 우1.30-2.15. 
Ventral spines on leg I and II. $\delta^{\lambda}$ : tibiae: I and II $0-0-0,0-$ $1 \mathrm{r}-0$ or $1 \mathrm{r}-1 \mathrm{r}-0$; metatarsi I $2-1 \mathrm{p}-0$ or 2-2-0, II 2-2-0. ㅇ: tibiae: I and II $0-0-0$ or $0-1 \mathrm{r}-0$; metatarsi I $2-0-0,2-1 \mathrm{p}-0,2-1 \mathrm{r}-$ $0,1 \mathrm{p}-2-0$ or $2-2-0$, II $2-0-0,2-1 \mathrm{p}-0,2-1 \mathrm{r}-0,2-2-0$.

Distribution. Japan (northern part of Okinawa-jima Island).

Note. Collecting date of the holotype of Z. flexuosus (NSMT-Ar 4319) is "27.VII.1997", which was missing in the original description (Kamura 1999).

\section{References}

Grimm, U. 1985. Die Gnaphosidae Mitteleuropas (Arachnida, Araneae). Abh. Naturwiss. Ver. Hamburg, (NF), 26: 1-318.

Kamura, T. 1987. Two new species of the genus Zelotes (Araneae: Gnaphosidae) from Japan. Akitu, N. Ser., 85: 1-7.

Kamura, T. 1994. A description of the female of Zelotes hayashii
Kamura, 1987 (Araneae: Gnaphosidae). Acta Arachnol., 43: 135137.

Kamura, T. 1999. Spiders of the genus Zelotes (Araneae: Gnaphosidae) from Ryukyu Islands, southwest Japan. Acta Arachnol., 48: 79-91.

Kamura, T. 2000. Three species of the genera Zelotes and Aphantaulax (Araneae: Gnaphosidae) from Japan. Acta Arachnol., 49: $159-164$.

Matsuda, M. 1988. Supplementary note (2) to "A list of spiders of the central mountain district (Taisetsuzan National Park), Hokkaido." Bull. Higashi Taisetsu Mus. Nat. Hist., 10: 11-18. (In Japanese)

Ono, H. 1994. Gnaphosid spiders mainly from the Daisetsuzan Mountains, Hokkaido, Japan. Acta Arachnol., 43: 183-191.

Paik, K.Y. 1986. Korean spiders of the genera Zelotes, Trachyzelotes and Urozelotes (Araneae: Gnaphosidae). Korean Arachnol., 2(2): 23-46.

Received March 10, 2003 / Accepted March 31, 2003 


\section{Acta Arachnologica Vol. 52, No. 1 掲載論文の和文要旨}

ゴミグモ（クモ目：コガネグモ科）のゴミリボンが餌捕獲に及 ぼす影響（pp. 1-3）

馬場友希（干113-8657 東京都文京区弥生 1-1-1 東京大学大 学院農学生命科学研究科生物多様性科学研究室)

本研究ではゴミグモ（Cyclosa octotuberculata）のゴミリボン が獲物の行動に影響を与え, 餌捕獲数に影響を及ぼすという仮 説を検証した，実験的にゴミリボンのある網と無い網を作成し， 野外で飭捕獲数を比較したところ有意な差はなかった。またそ の他の要因を考慮にいれて重回帰分析を行ったが, 餌捕獲数へ の影響はみとめられなかった。この結果よりゴミリボンが網上 の大きな構造物にも関わらず獲物に対して視覚的効果をむたな い可能性が考えられる.

札幌市近郊におけるザトゥムシの季節消長と生態, およびェゾ ナミザトウムシとその近縁種についての分類学的ノート（pp. 5-24)

鶴崎展巨（干680-8551 鳥取市湖山町南 4-101 鳥取大学教育 地域科学部生物学研究室)

札幌市近郊の 3 力所（野幌, 円山, 北大構内）に生息するザ トウムシ 11 種の季節消長と生態を調査した。ほとんどの種は 年 1 化卵越冬の生活史を示したが，フタコブザトウムシ Paraumbogrella pumilio は年 1 化成体越冬, マキノブラシザト ウムシ Sabacon makinoi では卵と幼体の両方での越冬が示唆さ れた。四国に生息するザトウムシと比較すると, 幼体越冬の種 を欠くことが北海道産種の生活史の特徴である. 卵越冬の種で は，春季により早く粰化する種ほど幼体期間が長かった。 また， 卵越冬のほとんどの種で雌が雄よりも早く成体に達する傾向 （雌先熟）がみられた。雌先熟は他のクモガ夕綱や昆虫では非 常に珍しいが，マザトウムシ上科 Phalangioidea のザトウムシ では一般的傾向と思われる。長い繁殖期間と雌の多数回交尾が 一般的であることが雌先熟傾向を生み出しているのかもしれな い. 土壌性の 3 種（ブラシザトウムシ属 Sabacon 2 種とフタコ ブザトウムシ P. pumilio）をのぞき, どの種も幼体初期には土 壌リタ一中で過ごすが，幼体期の途中から，草本層や樹幹へ日 中の生息場所を移した. 両生生殖の 3 種では性比は雄に偏る傾 向がみられた。雌先熟とも関係して, 性比は時間的にも変化し た. 7 種の産卵数と 10 種の卵サイズのデー夕を示した。ブラ シザトウムシ科の 2 種の卵のうを初めて記録した。さらに, 学 名が未決定であったエゾナミザトウムシに対して Nelima suzukii の名称を与え, ナミザトウムシ属の分類について若干 の知見を付記した。

韓国及び日本産のケムリグモ属（クモ目：ワシグモ科）数種に ついての分類学的検討 (pp. 25-30)

加村隆英（干567-8502 大阪府茨木市西安威 2-1-15 追手門学 院大学生物学研究室)
ケムリグモ属 Zelotes の数種について分類学的検討の結果を 報告した。韓国で記載されたミカドケムリグモ Z. kimwha Paik 1986 とZ. tintinnus Paik 1986 については，同一地点から採集さ れた雌雄の標本を検討した結果, 後者を前者の新参異名とした。 北海道に分布するコブシケムリグモ Z. hayashii Kamura 1987 と ビフカケムリグモZ. bifukaensis Kamura 2000 については, 前 者の雌雄及び後者の雄のみが知られており, 後者の雌は未知で あったが, 新たな標本を検討した結果, 従来コブシケムリグモ の雌とみなされていたものは正しくはビフカケムリグモの雌で あることが判明し，同時に，真のコブシケムリグモの雌も見出 された．沖縄産のリュウキュウケムリグモZ. ryukyuensis Kamura 1999 とッッ゙ラケムリグモZ. flexuosus Kamura 1999 に ついては, 前者の雌雄及び後者の雌のみが知られており, 後者 の雄は未知であったが, 沖縄島における再調査の結果, これら 2 種の雄の触肢の構造は互いに極めてよく似ており, リュウキュ ウケムリグモの雄とみなされていたものの中にッッ゙ラケムリグ モの雄が混じっていたことが判明した。

\section{東京都青梅市の山林から発見されたササラダニ類（イカダニ科） の 1 新種 (pp. 31-33)}

青木淳一（テ250-0031 小田原市入生田499 神奈川県立生命 の星・地球博物館）

青梅市の北部に広がる黒沢川沿いのコナラを主とする林の林 床の倒木の樹皮から,イカダニ科に属するササラダニ類の未記 載種が見出されたので Dolicheremaeus ohmensis オウメイカダ 二之命名して記載した. イカダニ科の多くの種では後体部前縁 に 2 対の瘤状突起があるが，本種を含めて 6 種では,その突起 が 1 対しかない，その中で本種は胴感毛の柄が短く先端部が強 く膨らむこと, 背毛が短いむのと著しく長いむのの 2 群に分か れることなどによって，既知の 5 種から区別される.

日本産キシダグモ科の 2 新種および 2 新記録種（pp. 35-42）

谷川明男（干248-0025 神奈川県鎌倉市七里力゙浜東 2-3-1 神 奈川県立七里ガ浜高等学校)

日本産キシダグモ科の 2 新種, Dolomedes orion n. sp.オオ八 シリグモ（新称）とDolomedes zatsun n. sp.ササキハシリグモ （新称）を記載し, Dolomedes horishanus Kishida 1936 ヘリジロ ハシリグモと Pisaura bicornus Zhang \& Song 1992 サイホウキ シダグモ（新称）の 2 種を日本から新たに記録し, 再記載した. また, Dolomedes yawatai Ono 2002 イシガキアオグロハシリグ モを西表島から新たに記録した。台湾から知られていた Dolomedes mizhoanus Kishida 1936 はへリジロハシリグモの新 参シノニムである. 